
ISSN: 2576-0971

journalbusinessentrepreneurial@gmail.com

Colloquium editorial

Ecuador

\title{
Influencia del comercio electrónico en el turismo
}

Fiallos Moncayo, Daniel

Influencia del comercio electrónico en el turismo

Journal of business and entrepreneurial studies, vol. 3, núm. 2, 2019

Colloquium editorial, Ecuador

Disponible en: http://www.redalyc.org/articulo.oa?id=573660685005

DOI: https://doi.org/10.31876/jbes.v3i2.24

Esta obra está bajo una Licencia Creative Commons Atribución-NoComercial-SinDerivar 4.0 Internacional. 


\title{
Influencia del comercio electrónico en el \\ turismo
}

\author{
Influence of electronic commerce in tourism \\ Daniel Fiallos Moncayo daniel.fiallom@ug.edu.ec \\ Universidad de Guayaquil, Ecuador \\ http://orcid.org/0000-0002-8083-9206
}

Journal of business and entrepreneurial studies, vol. 3, núm. 2, 2019

Colloquium editorial, Ecuador

Recepción: 13 Septiembre 2018

Aprobación: 09 Mayo 2019

DOI: https://doi.org/10.31876/ jbes.v3i2.24

Redalyc: http://www.redalyc.org/ articulo.oa?id $=573660685005$

\section{BY-NC-ND}

Resumen: La evolución de las nuevas tecnologías informáticas y de comunicaciones, como el internet y el comercio electrónico, han desarrollado la actividad comercial en el sector turístico, pues se ha podido mejorar la gestión empresarial, al encontrar en los medios sociales herramientas más efectivas para comercializar y distribuir los productos y servicios turísticos. Por lo que se ha visto la necesidad de analizar el desarrollo del comercio electrónico a nivel mundial, especialmente en los países de mayor desarrollo turístico como España y Estados Unidos, el crecimiento en los países de América Latina, y sin duda la apertura que Ecuador le ha dado a las nuevas tecnologías. Así como la relación que existe entre el Comercio Electrónico y la actividad turística, donde se explica las ventajas y desventajas que el E-Commerce a producido tanto en las empresas que brindan servicios turísticos como a sus potenciales clientes, y en especial a las empresas que prestan el servicio de transporte terrestre turístico en el país.

Palabras clave: Turismo, Comercio Electrónico, Tecnologías Informáticas, Internet, Ventas.

Abstract: The evolution of new information and communications technologies, such as the Internet and electronic commerce have developed the business in the tourism sector, as it has been able to improve corporate governance, finding social media tools to market and more effective distribution of tourism products and services. As has been the need to analyze the development of electronic commerce worldwide, especially in more developed countries such as Spain and tour the United States, growth in Latin American countries, and certainly the opening that Ecuador will has led to new technologies. Just as the relationship between electronic commerce and tourism, which explains the advantages and disadvantages of the E-Commerce has produced both companies that provide travel services and their potential clients, especially companies that provide ground transportation service resort in the country.

Keywords: Tourism, Electronic Commerce, Information Technology, Internet, Sales.

\section{Introducción}

"El comercio electrónico es una nueva manera de realizar negocios utilizando el internet, lo cual se está convirtiendo cada vez más en un estilo de vida de la era tecnológica actual. Básicamente se aprovecha que las actividades se realizan en línea, es decir se procesan las transacciones inmediatamente, las 24 horas del día durante los 7 días de la semana”. (Wilson Cueva Vera, 2003)

Pero debemos tomar en cuenta que el término E-Commerce como también se lo conoce no solo se refiere a la compra y venta de bienes o servicios, sino también a la producción, publicidad y distribución de bienes y servicios a través de las redes de telecomunicaciones que puede ser utilizado en cada uno de los departamentos que forman una empresa 
como son en el de Marketing, Recursos Humanos, Finanzas, Compras, etc (Bernal, 2006).

El turismo es una de las actividades pioneras en la utilización de la estrategia del comercio electrónico, lo que ha permitido que esta logre un gran desarrollo, convirtiéndose en la actualidad en unos de los pilares fundamentales en la economía de varios países. El transporte terrestre turístico es uno de los servicios imprescindibles dentro de la actividad turística, pues es el que se encarga del traslado de los turistas desde los centros de soporte como aeropuertos, hoteles, hacia los diferentes atractivos naturales y culturales que tienen como principal medio el transporte terrestre, y en la actualidad una de las estrategias de las empresas relacionadas a la actividad turística es estar relacionados con los avances tecnológicos, que permiten implementar cambios en la forma de realizar negocios, lo que permitirá alcanzar una mayor competitividad en el mercado, y a la vez satisfacer los requerimientos de turistas nacionales y extranjeros (Besley, 2006).

El turismo es uno de los sectores que más rápido convencieron a las personas de realizar su primera compra en línea, y en estos últimos años se ha enfocado en personalizar más la experiencia de los usuarios que planean sus viajes a través de internet, desarrollando nuevas herramientas para que los turistas puedan armar sus propios paquetes de viaje, además de reservar cualquier tipo de servicios turísticos por medio de aplicaciones móviles (Bonduki, 2007).

Viajes es la categoría que más aporta económicamente al comercio electrónico, y sin duda esto hace que se posicione como factor clave para el crecimiento de las ventas online en el país.

Materiales y métodos

El turismo es uno de los principales actores del comercio internacional y representa al mismo tiempo una de las principales fuentes de ingresos de los países en vías de desarrollo, convirtiéndose en un pilar fundamental para el desarrollo de la economía a nivel mundial (Brealeyy Myers, 1992).

La actividad turística es uno de los sectores más influenciados con la aparición de las Tecnologías de la Información y Comunicación como el internet y el comercio electrónico, convirtiéndose en herramientas fundamentales para el desarrollo de la actividad turística, pues se han creado nuevos modelos de negocio que intervienen en la estructura tradicional de los canales de distribución del turismo, pues son los principales afectados con la utilización de estas nuevas tecnologías, ya que las negociaciones se realizarán directamente entre las empresas que ofrecen los productos y servicios con los consumidores (Dede, 2007).

La importancia del turismo en el comercio electrónico es indiscutible, así como lo es internet para la industria turística, pues miles de jugadores (hoteleros, agencias de viaje, aerolíneas, etc.) han sabido aprovechar las ventajas que ofrece la red, y esto ha hecho que cada vez más personas consulten internet antes de iniciar un viaje, logrando posicionar a este medio como el preferido por los viajeros para planear y reservar viajes (Cely y Hernández, 2003). 
Definitivamente, el turismo ganó mayor protagonismo en el comercio electrónico, en comparación con otros sectores, porque encontró la manera de mejorar la experiencia de compra y de transferirle poder al usuario para que él elija los detalles de su viaje. De esta forma, el usuario es quien decide con qué aerolínea viajar, en qué hotel hospedarse, en dónde rentar un auto, entre otros servicios, de forma sencilla y en un solo lugar (Hernández y Baptista, 2003).

\section{Materiales y métodos}

La importancia y la necesidad de la utilización del Comercio Electrónico en la industria turística ayuda a mejorar las operaciones tradicionales practicadas en los negocios, tanto en la estrategia empresarial como en la reingeniería del negocio turístico. El hecho de que predominen las pequeñas y medianas empresas en el sector implica que la utilización del e-Commerce no se ha extendido todavía suficientemente, sin embargo, este puede ayudar a mejorar los procesos de gestión, control en la toma de decisiones, de estas empresas para que actúen de manera eficiente.

Existen diferentes tipos de comercio electrónico:

$\varnothing$ Comercio electrónico entre empresas (B2B): negocios de comercio entre empresas.

$\varnothing$ Comercio electrónico entre empresa y consumidor (B2C): negocios de comercio entre empresas y consumidores finales.

$\varnothing$ Comercio electrónico entre consumidores (C2C): negocios de comercio entre los propios consumidores.

$\varnothing$ Comercio electrónico entre consumidores o empresas y administración pública (C2A y B2A): negocios de comercio que se da entre empresas o consumidores y cualquier tipo de administración pública.

El Comercio Electrónico funciona como una vitrina gigante, en donde se anuncian todo tipo de productos y servicios que pueden ser apreciados por las personas en cualquier lugar del mundo a cualquier hora del día, acortando de esta manera las distancias, los aspectos geográficos y económicos (Méndez, 2006).

“...es la acción de realizar de forma electrónica transacciones comerciales. Esta basado en el tratamiento y transmisión electrónica de datos, incluidos textos, imágenes y videos. El Comercio Electrónico comprende actividades muy diversas como: comercio electrónico de bienes y servicios, suministros en línea de contenidos digitales, transferencia electrónica de fondos, compraventa electrónica de acciones, conocimientos de embarque electrónicos, subasta, diseños y proyectos conjuntos, prestación de servicios en línea, contratación pública, comercialización directa al consumidor y servicios postventa. Por otra parte, abarca a la vez productos (bienes de consumo, equipo médico especializado) y servicios (servicios de información, financieros y jurídicos), actividades tradicionales (asistencia sanitaria, educación) y nuevas actividades (centros comerciales virtuales...)". (MORENO N. 2002) 
El comercio electrónico consiste en la utilización de la Informática y las telecomunicaciones para canalizar los flujos de información y transacciones de negocio existentes entre una empresa y sus interlocutores de negocio habituales (clientes, proveedores, entidades financieras, transportistas, etc) (Pacheco, 2000).

\section{Resultados}

\section{Ventajas y Desventajas}

Ventajas del comercio electrónico en la oferta turística.

Las empresas pueden acceder fácilmente a mercados mundiales a bajos costos.

Reducir o eliminar a los intermediarios y tener un contacto directo con los clientes, ofreciéndoles precios más competitivos.

Que la empresa ofrezca mayor competitividad, al contar con un sistema de comunicación más efectivo tanto dentro como fuera de la empresa.

Herramienta fundamental en el plan de marketing, al poder contar con la página web, formar parte en las redes sociales, etc.

Contar con una base de datos, que le permita conocer las exigencias de los consumidores y de la competencia.

Ventajas del comercio electrónico en la demanda turística.

Los potenciales consumidores podrán elegir de una gran variedad de productos y servicios.

Contar con una información clara y precisa sobre los productos y servicios.

Permite comparar una gran cantidad de oferta turística.

Encontrar precios más bajos en comparación con los que ofrecen las intermediadoras.

El poder realizar la compra desde el hogar, sin tener que desplazarse hacia las intermediadoras.

Desventajas del comercio electrónico en la actividad turística.

Rechazo a la adquisición de productos por medio de los nuevos procesos, por la falta de conocimiento de la utilización de estas herramientas.

Dificultad a la hora de tomar una decisión por parte de los clientes.

Desconfianza en los consumidores en las transacciones y en las formas de pago.

Resistencia al abandono de la comercialización tradicional, por no poder evaluar la fiabilidad del vendedor y de los productos y servicios que ofrecen.

No contar con un marco legal que respalde las transacciones.

Saturación en los sistemas de comunicación, ocasionando lentitud al momento de abrir alguna página.

Altos costos para adquirir equipos informáticos, medios de seguridad y una conexión efectiva.

La diferencia a nivel tecnológico y de la mentalidad en cada país, lo que permitirá que algunos países evolucionen más rápido que otros. 


\section{Discusión}

Que la aplicación de las Nuevas Tecnologías en la actividad turística en especial el E-Commerce ha traído el avance del sector turístico, permitiendo que este pueda aumentar el ingreso económico en muchos países, y nuestro país no se ha quedado atrás al implementar esta herramienta, pero al realizar este ensayo me pude dar cuenta la brecha digital que existe entre las grandes empresas y las medianas y pequeñas empresas, ya que las pymes por el algo costo que les genera el implementar estas herramientas, tienen que verse alejadas del mundo de las compras y ventas online.

Las ventajas del Comercio Electrónico (E-Commerce) van más allá del simple posicionamiento o mejoramiento del mismo, tienen que ver con el incremento de la competitividad y la oportunidad de generar una estrategia de desarrollo y mejoramiento continuo, estableciendo al turismo como una actividad económica sostenible y sustentable para la sociedad de cualquier región.. El turismo es característico por su diversidad cultural y su valor universal, características que se pueden magnificar a través del adecuado uso de herramientas tecnológicas que le brinden a las diversos destinos y sus organizaciones, una manera eficiente de gestionar sus relaciones comerciales. Aun cuando el comercio electrónico y las TIC's se encuentran en boga, es innegable que el desarrollo alcanzado por algunas regiones del mundo es muy inferior al de aquellas que son generadoras de los grandes avances tecnológicos, donde las sociedades están acostumbradas a la interacción virtual, sea esta o no con fines comerciales.

\section{Conclusión}

El turismo y sus organizaciones, fundamentalmente sus entidades económicas como en el caso de las PyMEs, requieren replantear su modelo de negocios y comercialización, ya que, aun cuando se conoce la importancia de dichas unidades económicas, también es bien sabido que estás se caracterizan por su reluctancia a la adquisición e implementación tecnológica, ya sea porque lo consideran onerosa o innecesaria. $\mathrm{La}$ principal recomendación corre en el sentido que la renovación en tiempos donde el modelo negocios evoluciona de la mano de los grandes avances tecnológicos, es prácticamente un suicidio negarse adoptar una estrategia comercial ad-hoc con dicha evolución. La sociedad y la demanda cambian diariamente, cada generación tiene sus características de búsqueda y consumo, como diría Dave Evans "el ciclo de vida del cliente: preventa, venta, renovación, actualización, etc.” (Evans, D., 2008) es diferente dependiendo del mercado meta al que está dirigido, pero indudablemente debe diseñarse una estrategia de e-tur que permita que las organizaciones turísticas y los destinos estén mejor preparados para atrapar la atención de los diversos segmentos que hoy en día habitan en la red de redes. 


\section{Referencias}

Moreno, N., (2002). Derecho-e Derecho del Comercio Electrónico. MadridEspaña: Marcial Pons Ediciones Jurídicas S.A

Bonduki, N. (2009). Política de vivienda e inclusión social en Brasil: revisión histórica y nuevas perspectivas en el gobierno Lula. En J. Erazo (coord.), Inter/secciones urbanas: origen y contexto en América Latina(pp.95-135). Quito: FLACSO - Sede Ecuador : Ministerio de Cultura del Ecuador.

Evans, D. (2008). Los medios sociales que comercializan una hora al día. Indianápolis. Estados Unidos: Wiley Publishing, Inc.

Cueva, W., (2003). Una Visión del Comercio Electrónico en el Ecuador. Revista de la Facultad de Ciencias Económicas de la Universidad de Cuenca, 10.

Bernal, C., (2006) Metodología de la investigación. Segunda edición. Editoriales Pearson - Prentice Hall. México 2006

Besley, S. y Brigham, E. F., (2005). Fundamentos de administración financiera. 12a. edición. México: McGraw-Hill

Brealey, Myers y Allen (1992). Principios de finanzas corporativas. 3a. ed. Caracas: McGraw-Hill

Cely, N. y Hernández, I., (2003), Redes de competitividad y productividad compartida. Quito - Ecuador: Stratega

Instituto del tercer mundo. (2003). El derecho a la vivienda adecuada. Recuperado de: http://hic-gs.org/content/Online/Dede.pdf

Hernández, R., et al. (2003) Metodología de la investigación. 6a ed. México D. F.: McGraw-Hill

Mendez, C., (2006). Metodología, diseño y desarrollo del proceso de investigación con énfasis en ciencias empresariales. 4ta edición. Bogotá - Colombia: Editorial Limusa.

Pacheco, O., (2000). Investigación I. Primera Edición. Guayaquil - Ecuador 2000:Editorial Mundiciencia. 